\title{
Review
}

\section{Non-apoptotic functions of BCL-2 family proteins}

\author{
Atan Gross ${ }^{*, 1}$ and Samuel G Katz \\ The BCL-2 family proteins are major regulators of the apoptosis process, but the mechanisms by which they regulate this process \\ are only partially understood. It is now well documented that these proteins play additional non-apoptotic roles that are likely to be \\ related to their apoptotic roles and to provide important clues to cracking their mechanisms of action. It seems that these \\ non-apoptotic roles are largely related to the activation of cellular survival pathways designated to maintain or regain cellular \\ survival, but, if unsuccessful, will switch over into a pro-apoptotic mode. These non-apoptotic roles span a wide range of \\ processes that include the regulation of mitochondrial physiology (metabolism, electron transport chain, morphology, \\ permeability transition), endoplasmic reticulum physiology (calcium homeostasis, unfolded protein response (UPR)), nuclear \\ processes (cell cycle, DNA damage response (DDR)), whole-cell metabolism (glucose and lipid), and autophagy. Here we review all \\ these different non-apoptotic roles, make an attempt to link them to the apoptotic roles, and present many open questions for \\ future research directions in this fascinating field.
}

Cell Death and Differentiation (2017) 24, 1348-1358; doi:10.1038/cdd.2017.22; published online 24 February 2017

Facts

- BCL-2 family members interact with each other and with resident mitochondrial proteins at the outer mitochondrial membrane to regulate the extrinsic and intrinsic pathways of apoptosis.

- BCL-2 family members are also distributed widely throughout the cell where they contribute to the regulation of numerous additional cellular functions.

- Several of the non-apoptotic functions of BCL-2 family members have a feed-back to apoptosis.

- Some of the non-apoptotic functions of BCL-2 family members seem to be completely distinct from their role in apoptosis.

\section{Open Questions}

- How are the non-apoptotic functions of distinct BCL-2 family proteins related to or exclusive from their apoptotic function? What determines when a BCL-2 family protein acts in one function versus another?

- Are there pathologic disease states dependent on nonapoptotic functions of BCL-2 family proteins?

- What are the protein domains and interacting proteins responsible for the non-apoptotic functions of BCL-2 family proteins?

- What are the appropriate cellular contexts for the nonapoptotic functions?

- How do BCL-2 family proteins regulate non-apoptotic functions of caspases?

\section{Introduction: BCL-2 Proteins as Regulators of Mitochondrial Apoptosis}

Programmed cell death, or apoptosis, is critical to both development and maintenance of tissues, and the BCL-2 family proteins are the major regulators of the apoptotic process. ${ }^{1}$ The mechanisms by which BCL-2 family proteins regulate cell death are largely unknown, though it is thought that their function depends mostly on their ability to modulate the release of proteins from the intermembrane space of the mitochondria. The BCL-2 family includes both pro- (e.g., BAX) and anti- (e.g., BCL-2) apoptotic proteins that possess up to four conserved BCL-2 homology domains (BH1-4) with the $\mathrm{BH} 3$ functioning as a death domain (Figure 1). A subset of the pro-apoptotic proteins is the $\mathrm{BH}$-only group of proteins (e.g., BID).

The BH3-only members are pivotal sensors/mediators of cellular stress, and once activated are known to perform two tasks: (1) inactivate the anti-apoptotic BCL-2 family members (e.g., BCL-2), and (2) activate the pro-apoptotic BCL-2 family members BAX and BAK (Figure 2). These two events are thought to occur in parallel, eventually resulting in mitochondrial outer membrane permeabilization (MOMP), cytochrome $c$ release, caspase activation, and apoptosis. However, it remains a long-lasting debate whether both events, inhibition of anti-apoptotics and activation of pro-apoptotics, are absolutely required for the execution of apoptosis at the mitochondria. ${ }^{2}$ Another important question that may shed light on the first question is whether BCL-2 family proteins play

${ }^{1}$ Department of Biological Regulation, Weizmann Institute of Science, 100 Herzel Street, Rehovot, Israel and ${ }^{2}$ Department of Pathology, Yale University School of Medicine, 310 Cedar Street, Brady Memorial Laboratory 127A, New Haven, CT 06520, USA

${ }^{*}$ Corresponding author: A Gross, Department of Biological Regulation, Weizmann Institute of Science, 100 Herzel Street, Rehovot 76100, Israel. Tel: +972 8 9343656; Fax: +972 8934 4116; E-mail: atan.gross@weizmann.ac.il

or SG Katz, Department of Pathology, Yale University School of Medicine, 310 Cedar Street, Brady Memorial Laboratory 127A, New Haven CT 06520, USA. Tel: +203 785 2757; E-mail: samuel.katz@yale.edu

Received 11.12.16; revised 26.1.17; accepted 30.1.17; Edited by E Arama; published online 24.2.17 


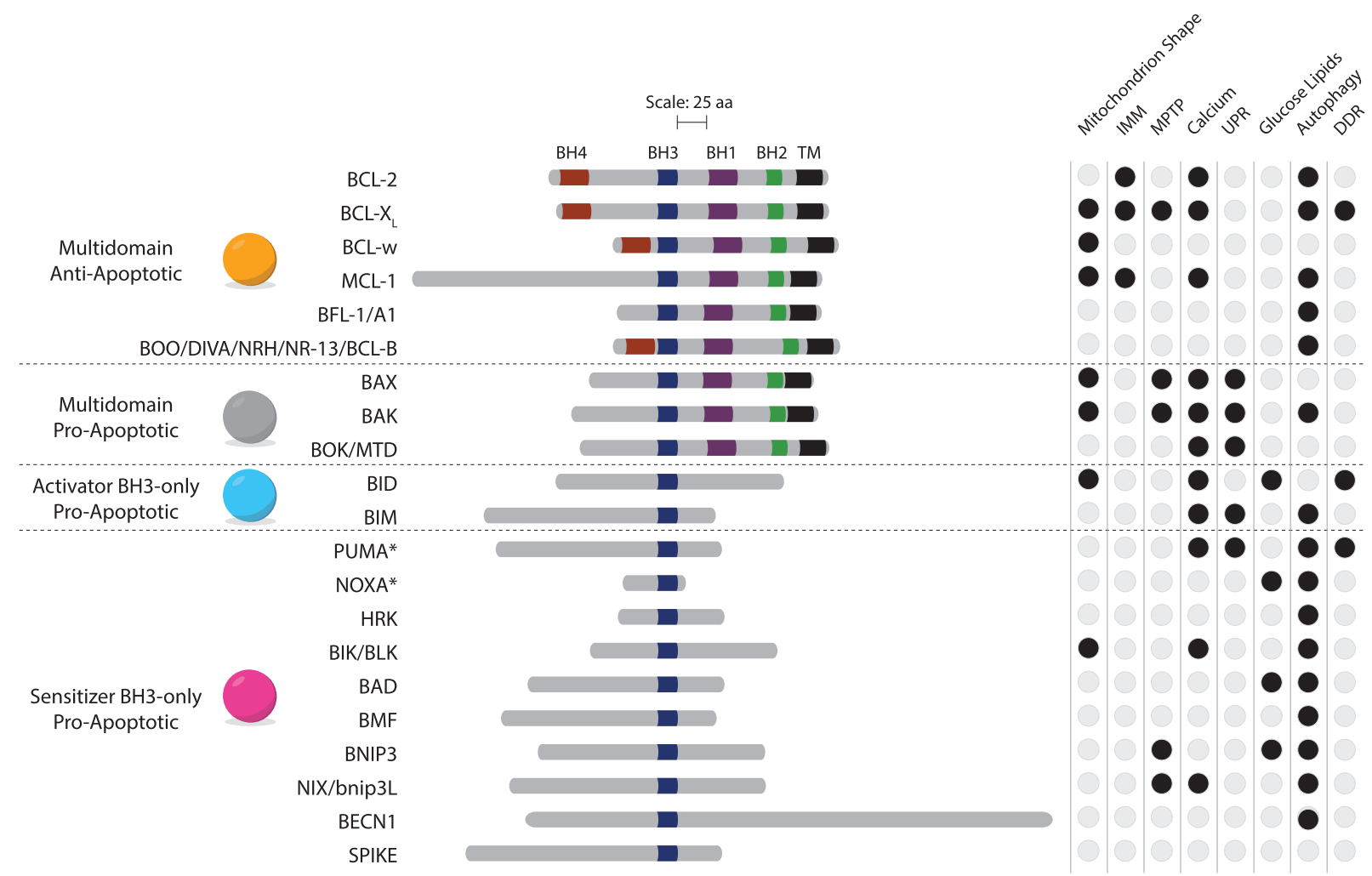

Figure 1 Classification of BCL-2 family members. BCL-2 family members are grouped by their ability to inhibit or activate apoptosis. Shared, conserved BCL-2 homology (BH) domains and transmembrane (TM) regions are depicted. *Indicates recent evidence for BH3-only proteins that might also act as activator BH3-only pro-apoptotic proteins. Darkened circles indicate where there is evidence to support an alternative function for the BCL-2 family member

additional roles related to mitochondrial function and whether these roles are related to their apoptotic role.

\section{Regulation of Mitochondrial Morphology}

Many of the BCL-2 family proteins reside at, or dynamically move on and off, the outer mitochondrial membrane (OMM). ${ }^{1}$ It is well established that under apoptotic conditions, the $\mathrm{BCL}-2$ proteins regulate MOMP, and this event is always accompanied by mitochondrial fission. Moreover, upon induction of apoptosis, DRP1, a dynamin-related protein that mediates OMM fission, translocates to the mitochondria to induce fission, and its inhibition blocks apoptosis. ${ }^{3}$ In addition, during the initial stages of apoptosis, BAX colocalizes with DRP1 at mitochondria scission sites, and mitochondrial fusion is blocked independently of caspase activation. ${ }^{4}$ Taken together, these pioneering studies from the Youle group ${ }^{4}$ led to an exciting working hypothesis that mitochondrial fusion/ fission (dynamics) is involved in MOMP, and that BCL-2 family members may also regulate mitochondrial dynamics under apoptotic (and perhaps also under non-apoptotic) conditions (Figure 3, middle panel).

In 2006, Karbowski et al. ${ }^{5}$ elegantly demonstrated that in healthy cells BAX or BAK is required for normal fusion of mitochondria into elongated tubules, and that BAX seems to induce fusion via activation of MFN2, another dynamin family protein that mediates OMM fusion. Another study has shown that BAK regulates mitochondrial fragmentation during apoptosis via interaction with MFN1 and MFN2. ${ }^{6}$ Moreover, it was demonstrated in a cell-free system of mitochondrial fusion that recombinant BAX positively stimulates fusion through MFN2. ${ }^{7}$ In this respect, it is interesting to note that increasing the mitochondrial levels of BH3-only BID (by loss of its phosphorylation by the ataxia-telangiectasia mutated (ATM) kinase) or knocking out $\mathrm{MTCH} 2$, the mitochondrial receptor for $\mathrm{BH}$-only $\mathrm{BID},{ }^{8}$ results in increased mitochondrial size/volume, and is associated with hematopoietic stem cell (HSC) mobilization and entry into active cell cycle. ${ }^{9,10}$ This suggests that $\mathrm{MTCH} 2$ is possibly involved in regulating mitochondrial dynamics, and that the pro-apoptotic BCL-2 family members can possibly act via $\mathrm{MTCH} 2$ to regulate the structure of mitochondria.

Regulation of mitochondrial dynamics is not exclusively mediated by the pro-apoptotic BCL-2 family members, as it was demonstrated that anti-apoptotic $B C L-X_{L}$ also regulates mitochondrial dynamics via DRP1. ${ }^{11,12}$ In this respect, an interesting chimera between $B C L-X_{L}$ and $B A X\left(B C L-X_{L} / B A X-\right.$ helix 5) induces substantial mitochondrial fragmentation in healthy cells via binding to mitofusins. ${ }^{13}$ It was also shown that CED-9, the worm BCL-2 relative, promotes mitochondrial fusion via FZO-1/MFN1,2 and EAT-3/OPA1 in both mammalian cells and in C. elegans. ${ }^{14,15}$ In addition, in Drosophila it has been demonstrated that Buffy and DEBCL, the BCL-2 fly relatives, affect mitochondrial dynamics, whereas there is no clear evidence for their involvement in apoptosis. ${ }^{16}$

In summary, the findings described above demonstrate that BCL-2 family members - in mammals, insects, and roundworms - are involved in the regulation of mitochondrial dynamics in both healthy and apoptotic cells. However, the 

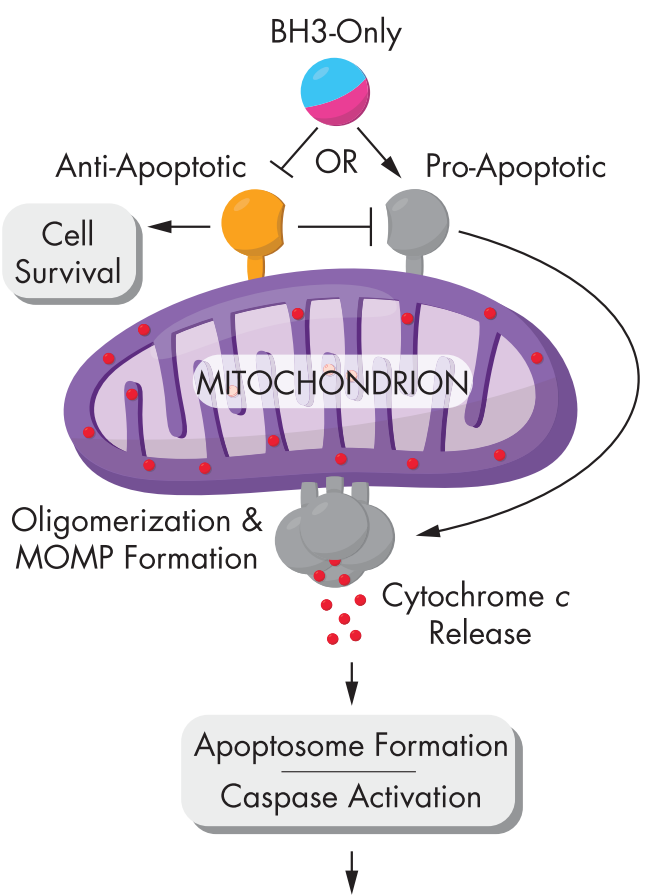

Apoptosis

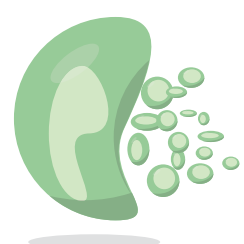

Figure 2 The intrinsic pathway of apoptosis. In response to stress signals, interactions among the different classes of BCL-2 family members at the outer mitochondrial membrane determine whether the cell is to survive or whether multidomain pro-apoptotic family members oligomerize and lead to mitochondrial outer membrane permeabilization (MOMP) with the release of several factors, including cytochrome $c$, thereby committing the cell to apoptosis

exact molecular mechanisms underlying how BCL-2 family members activate/inactivate the mitochondria dynamics machineries, and how these non-apoptotic functions may affect mitochondrial fragmentation during apoptosis, remain to be elucidated.

\section{Regulation of the Mitochondrial Permeability Transition Pore}

The mitochondrial permeability transition pore (MPTP) is a poorly characterized protein complex that mediates a regulated form of necrotic cell death. ${ }^{17}$ Distinct from the BAX/BAK oligomers that lead to MOMP, the MPTP perforates both the inner and outer mitochondrial membrane leading to a loss of inner membrane potential, dissolution of ATP synthesis, massive swelling due to an influx of water into the solute-rich matrix, and eventual organelle rupture and cell death. Early evidence that BAX and BAK played a role in MPTP distinct from MOMP came from their interaction with the presumed components adenine nucleotide translocator (ANT) and voltage-dependent anion channel (VDAC) ${ }^{18,19}$ (Figure 3, left panel). However, the MPTP components remain elusive as the complete deletion of both ANT1 and 2 as well as all three VDAC genes show that neither protein is directly required for MPTP formation. ${ }^{20,21}$ Recently, however, it has been demonstrated that the F-ATP synthase forms the MPTP. ${ }^{17}$ Nonetheless, BAX and BAK still appear to be required for mitochondrial poredependent necrotic death as their loss inhibits mitochondrial swelling and rupture. ${ }^{22,23}$ Moreover, this does not appear to be dependent on their ability to oligomerize and undergo MOMP as an oligomerization-deficient BAX mutant still permits MPTPdependent mitochondrial swelling and necrotic cell death. ${ }^{22,23}$ The mechanism by which BAX and BAK promote MPTP is still under investigation, with some data supporting a role for BAX-driven mitochondrial fusion as a means to lower the threshold for MPTP opening ${ }^{22}$ and other data suggesting that $\mathrm{BAX}$ and BAK act as outer membrane permeability factors in their monomeric states. ${ }^{23}$ Understanding the particular mechanism by which BAX and BAK influence MPTP is important in the development of targeting molecules to regulate this process.

\section{Regulation of Metabolism at the Inner Mitochondrial Membrane}

Several key pieces of data support distinct roles for BCL-2, $B C L-X_{L}$, and $M C L-1$ at the inner mitochondrial membranes (IMMs) (Figure 3, right panel). BCL-2 was originally biochemically purified as an IMM protein where it was hypothesized to function through various mitochondrial metabolic functions. ${ }^{24}$ Identification of a carboxy-terminal anchor sequence shifted focus to functions at the OMM. ${ }^{25}$ However, subsequent work confirmed that BCL-2 localizes to the IMM, ${ }^{26}$ and a few reports suggest that it regulates mitochondrial respiration and binds to cytochrome $c$ oxidase (COX) Va and cyclophilin D. ${ }^{27,28}$ Further exploration will be necessary to determine the physiological contexts under which BCL-2 utilizes these additional functions and how that interplays with its role in cell death at the OMM.

$B C L-X_{L}$ also localizes to the IMM where it interacts with the $F_{1} F_{0}$ ATP synthase and is important for the maintenance of the mitochondrial membrane potential. $^{29}$ Overexpression of $B C L-X_{L}$ in resting neurons leads to a twofold increase in cytoplasmic ATP levels, whereas loss of BCL- $X_{L}$ by genetic or pharmacologic inhibition increases mitochondrial ion leak and decreases ATP synthase function. Thus, BCL- $X_{L}$ prevents the non-ATP producing proton leak into the matrix by directly modulating the $F_{1} F_{0}$ ATP synthase and helps enhance ATP production under conditions of increased energy demand that improves cellular survival in a BAX/BAK-independent but $F_{1} F_{0}$ ATP synthase-dependent manner. ${ }^{29}$ In addition to its role in cellular survival, BCL- $X_{L}$ increases synaptic transmission in neurons by increasing the numbers and size of synapses and the localization of mitochondria to synapses and synaptic vesicles through direct interaction with DRP1. ${ }^{12}$ Precedent for a role in synaptic function was seen earlier by BAK that was surprisingly found to have an anti-apoptotic role protecting mice from kainite-induced seizures via synaptic activity regulation. ${ }^{30}$ Taken together, $B C L-X_{L}$ functions at the IMM by binding to the $F_{1} F_{0}$ ATP synthase in order to regulate pathways both directly involved in cell survival and distinct from it.

MCL-1 has also recently been demonstrated to be part of the group of anti-apoptotic BCL-2 family members that operate 

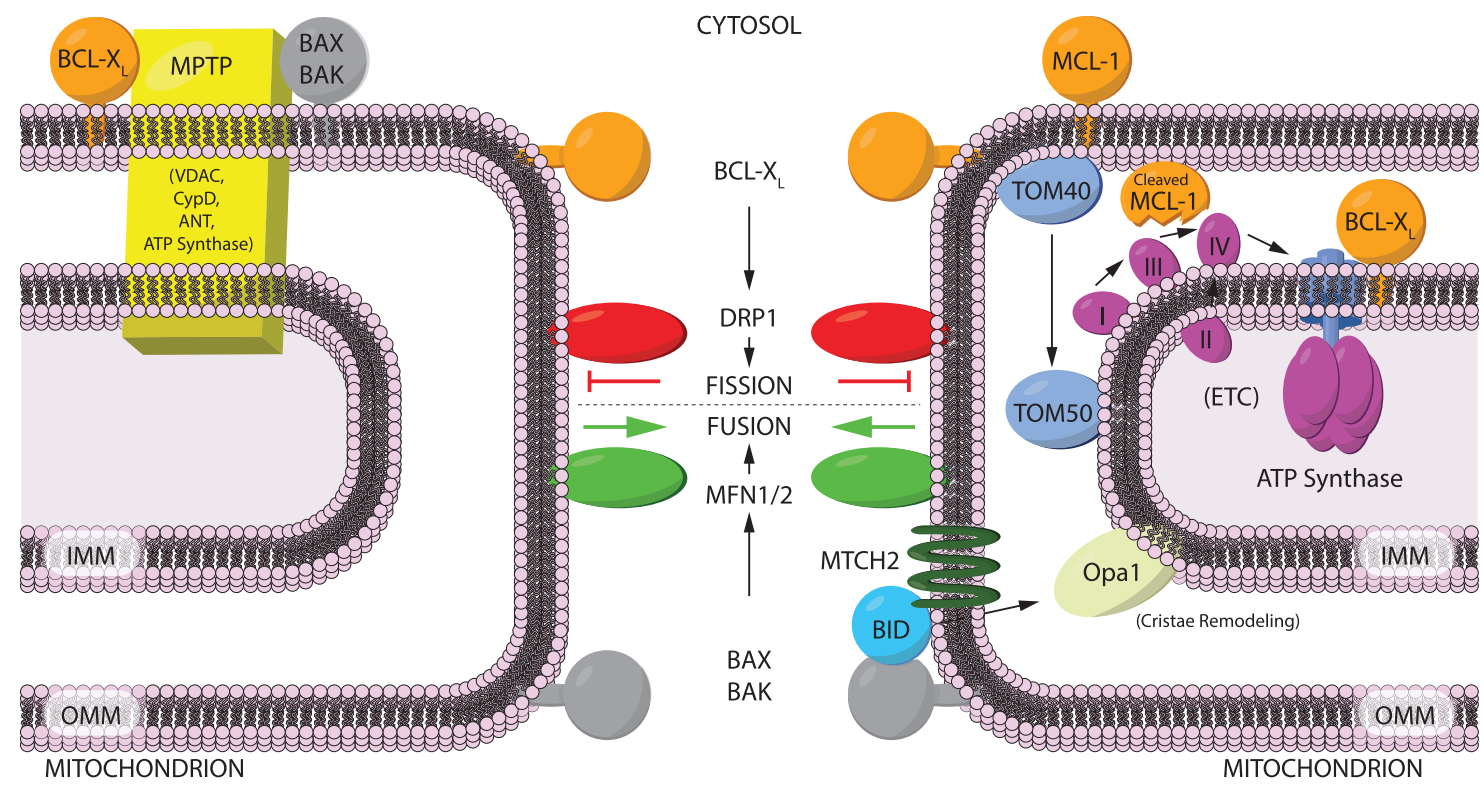

Figure 3 Alternative functions for BCL-2 family members at the mitochondria. BCL-2 family members have functions in regulation of the mitochondrial permeability transition pore (MPTP) (left), the process of mitochondrial fusion and fission (middle), and in regulation of oxidative phosphorylation through the electron transport chain (ETC) in the inner mitochondrial membrane (right), as discussed in the text

at the IMM. ${ }^{31}$ IMM import for MCL-1 requires two proteolytic cleavage sites, a mitochondrial targeting sequence, and translocases of the OMM (TOM40) and IMM (TIM50). ${ }^{31} \mathrm{Mcl}-1$ deletion results in a number of mitochondrial defects, including (1) disorganized mitochondrial cristae, (2) loss of the tubular mitochondrial network, (3) decreased enzymatic activity of complex I (NADH dehydrogenase), complex II (succinate dehydrogenase) and complex III (cytochrome coxidase), (4) decreased formation of respiratory supercomplexes and $F_{1} F_{0}$ ATP synthase higher-order oligomers, and (5) decreased ATP levels and oxygen consumption rates. ${ }^{31}$ The close interdependence of these various features of mitochondrial structure, function, and dynamics makes it difficult to precisely determine the role of MCL-1 within this system. However, an MCL-1 isoform that only localizes to the IMM rescues the mitochondrial abnormalities, but does not provide anti-apoptotic activity in response to staurosporine or etoposide, whereas the opposite is observed with an MCL-1 isoform that only localizes to the OMM. ${ }^{31}$ It will be of great interest to determine the relative contributions of the distinct functions of MCL-1 in apoptosis and mitochondrial function to its various physiological roles in development as well as in oncogenesis. Interestingly, loss of MCL-1 leads to a rapidly lethal cardiomyopathy that appears to be dependent on its apoptotic role as loss of BAX and BAK completely rescues the cardiac function despite the continued presence of mitochondrial ultrastructural and functional abnormalities. ${ }^{32}$

\section{Regulation of Calcium Homeostasis at the Endoplasmic Reticulum}

Multiple BCL-2 family members have been shown to regulate endoplasmic reticulum (ER) calcium by binding to the various inositol 1,4,5-trisphosphate receptors (IP3R1-3) ${ }^{33}$ (Figure 4, right panel). The IP3Rs are ubiquitous, ER-resident, calcium release channels that are essential for numerous calcium signaling pathways. BCL-2, BCL- $X_{L}$, and $M C L-1$ each bind to the sixth transmembrane domain of the IP3R. ${ }^{34,35}$ This interaction enhances calcium leak from the ER because of an allosteric shift that sensitizes the IP3R to very low IP3 levels present in resting cells. ${ }^{34,35}$ In addition, BCL-2 also binds the middle of the IP3R regulatory region through its $\mathrm{BH} 4$ domain whereby it inhibits large, stress-induced release of calcium. ${ }^{36}$ NRZ, a zebrafish anti-apoptotic homolog, also inhibits IP3induced calcium release, but does so by competitive inhibition at the IP3 binding domain. ${ }^{37}$ Beyond the IP3R, BCL-2 binds and inactivates the main ER calcium importer, the sarco/ endoplasmic reticulum $\mathrm{Ca}^{2+}$ ATPase (SERCA) pump, ${ }^{38}$ induces a decline in SERCA2b levels, ${ }^{39}$ and even functions in increasing calcium extrusion from the cell through the calcium pumps in the plasma membrane. ${ }^{40}$ The ability of BCL-2 to regulate cellular calcium levels at multiple levels may be important in order to establish an integrated handling of calcium throughout the cell.

Pro-apoptotic BCL-2 family members have also been implicated in IP3R-mediated calcium regulation. ${ }^{41,42}$ The loss of BAX and BAK results in an increase in IP3R1 calcium leak leading to a reduced calcium resting concentration in the ER and a decreased uptake of calcium in the mitochondria. ${ }^{42,43}$ Although BAX and BAK do not directly bind to the IP3Rs, BAX/ BAK interaction with the anti-apoptotic proteins may compete away anti-apoptotic-IP3R binding. In the absence of BAX and BAK, there is increased BCL-2 and IP3R 1 binding and IP3R1 hyperphosphorylation, making it sensitive to basal IP3 levels. ${ }^{43}$ Similarly, tBID antagonizes BCL- $\mathrm{X}_{\mathrm{L}}$ enhancement of IP3R-calcium release by blocking its interaction with the IP3R. ${ }^{35}$ BIK, NIX, and PUMA also contribute to ER calcium depletion in a BAX/BAK-dependent manner. ${ }^{44-46}$ In contrast, 


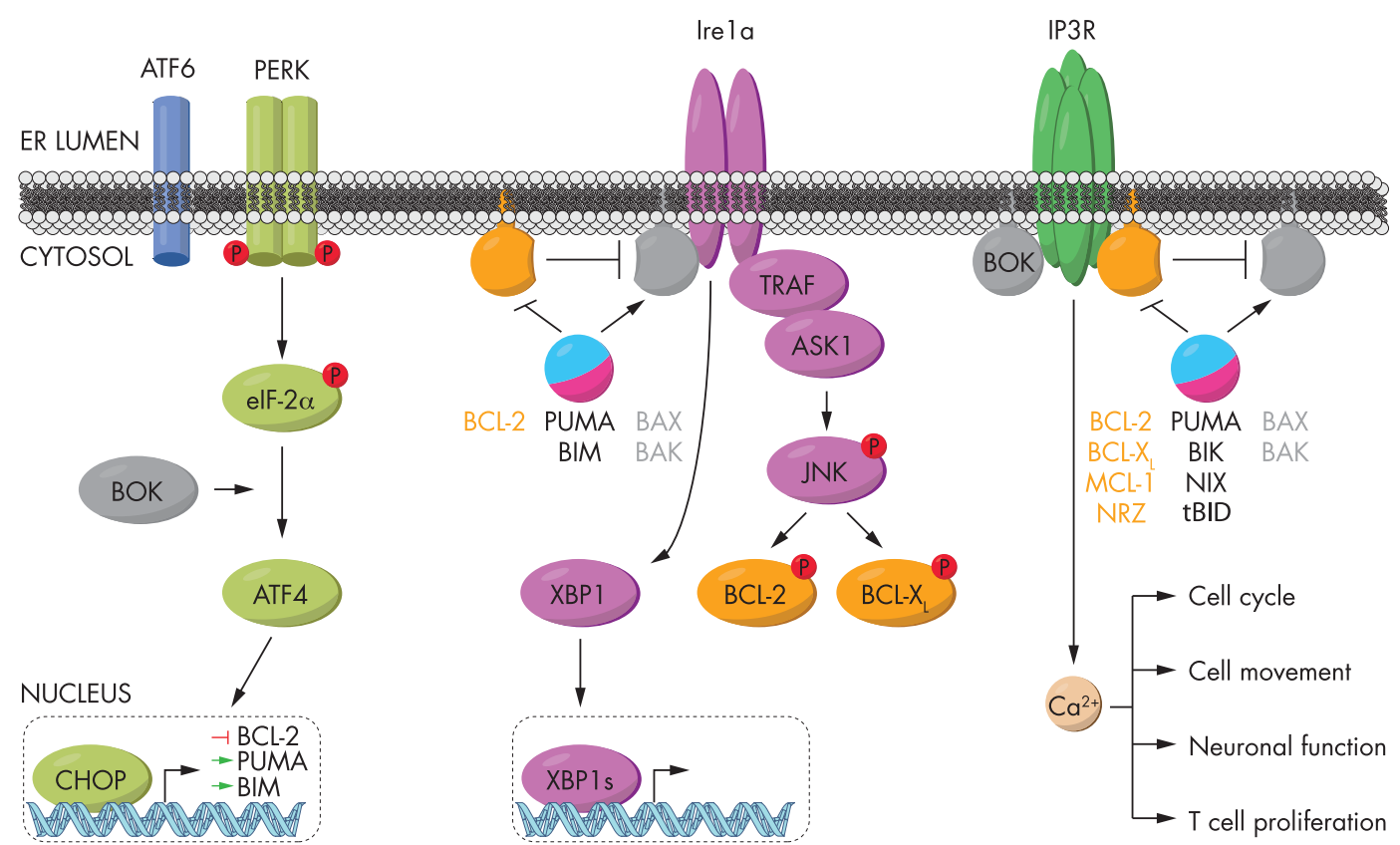

Figure 4 Alternative functions for BCL-2 family members at the endoplasmic reticulum. BCL-2 family members have functions in regulation of the unfolded protein response for PERK signaling (left) and IRE- $1 \alpha$ signaling (middle) as well as in regulation of calcium release by the IP3R (right)

BOK does bind to the IP3R, ${ }^{41}$ but might not bind to antiapoptotic BCL-2 family members. ${ }^{47}$ The binding of BOK BH4 domain to IP3R regulatory domain results in reciprocal protection from degradation, by caspase 3 for IP3Rs ${ }^{41}$ and by the proteasome for $\mathrm{BOK} .{ }^{48}$ Surprisingly, initial experiments did not reveal a major effect of BOK on the calcium mobilizing function of IP3Rs in response to IP3 in permeabilized MEFs. ${ }^{41}$ However, Bok ${ }^{-1-}$ primary cortical neurons did reveal a decreased, but prolonged rise in cytoplasmic calcium levels in response to NMDA excitotoxicity. ${ }^{49}$ Further elucidation of BOK regulation of IP3R calcium dynamics and its relationship to apoptosis is an important area of inquiry.

BCL-2 family members are able to affect numerous cellular pathways beyond cell death through their regulation of calcium, a well-known second messenger system. BCL-2 and $B C L-X_{L}$ promote $G 1$ arrest through elevation of the calcium-regulated, cyclin-dependent kinase inhibitor p27, whereas BAX promotes S-phase entry through p27 depression. ${ }^{50,51}$ Mutation of BCL-2 BH4 domain affects IP3induced calcium release and BCL-2 regulation of the cell cycle, but not its anti-apoptotic function. ${ }^{52}$ Cell movement is regulated in early vertebrate development by NRZ control of calcium and cytoskeletal dynamics ${ }^{37}$ as well as in cancer cell invasion by BCL-2. ${ }^{53}$ T-cell proliferation is dependent on BAX, $B A K$, and BIM, where loss of BAX and BAK from T cells leads to ER calcium store reductions and defects in T cell receptorinducible calcium fluxes necessary for T-cell proliferation. ${ }^{54}$ Similarly, loss of BIM from T cells leads to increased BCL-2IP3R complexes, lower ER calcium release, and decreased NFAT activity. ${ }^{55}$ Finally, overexpression of BCL-2 in CNS neurons promotes axonal growth, whereas deletion reduces axonal elongation. ${ }^{56}$ This function requires BCL-2 to localize to the ER and is mediated by ERK and CREB that are activated by cytosolic calcium. ${ }^{57}$ In fact, a single-nucleotide polymorphism (SNP) associated with bipolar disorder leads to decreased BCL-2 expression and abnormal IP3R release of calcium. ${ }^{58}$ Taken together, calcium regulation by BCL-2 family members has a broad reach in regulating cellular processes like cell cycle, invasion, activation, and growth.

\section{Regulation of the Unfolded Protein Response}

The second major pathway in the ER affected by BCL-2 family members is the unfolded protein response (UPR). In this signaling pathway, three ER transmembrane proteins, IRE1a (inositol requiring enzyme 1), PERK (protein kinase like ER kinase), and ATF6 (activating transcription factor 6), are activated by the accumulation of misfolded proteins because of a variety of cellular stresses. ${ }^{59}$ Altogether, the three arms of the UPR activate a cellular survival pathway designed to regain cellular homeostasis, but, if unsuccessful, will switch over into a pro-apoptotic pathway. The exact mechanism by which the UPR switches from an adaptive response to a prodeath pathway is still unclear.

IRE $1 a$ contains both an endoribonuclease domain and a kinase domain. Through the kinase domain, IRE1a communicates ER stress ultimately to JNK that phosphorylates and inhibits the anti-apoptotic functions of BCL-2 and BCL- $X_{L}^{60,61}$ (Figure 4, middle panel). In contrast, BAX and BAK bind IRE1a to modulate the amplitude of its signaling, such that $\mathrm{Bax}^{-/} \mathrm{Bak}^{-/}$cells exhibit decreased endoribonuclease activity under ER stress. ${ }^{62}$ The RNAse activity of IRE1a participates both in general RNA degradation to reduce protein synthesis ${ }^{63}$ and direct splicing of a few target genes, including the transcription factor XBP-1 (X-box binding protein 1) that activates several genes that help restore ER folding 


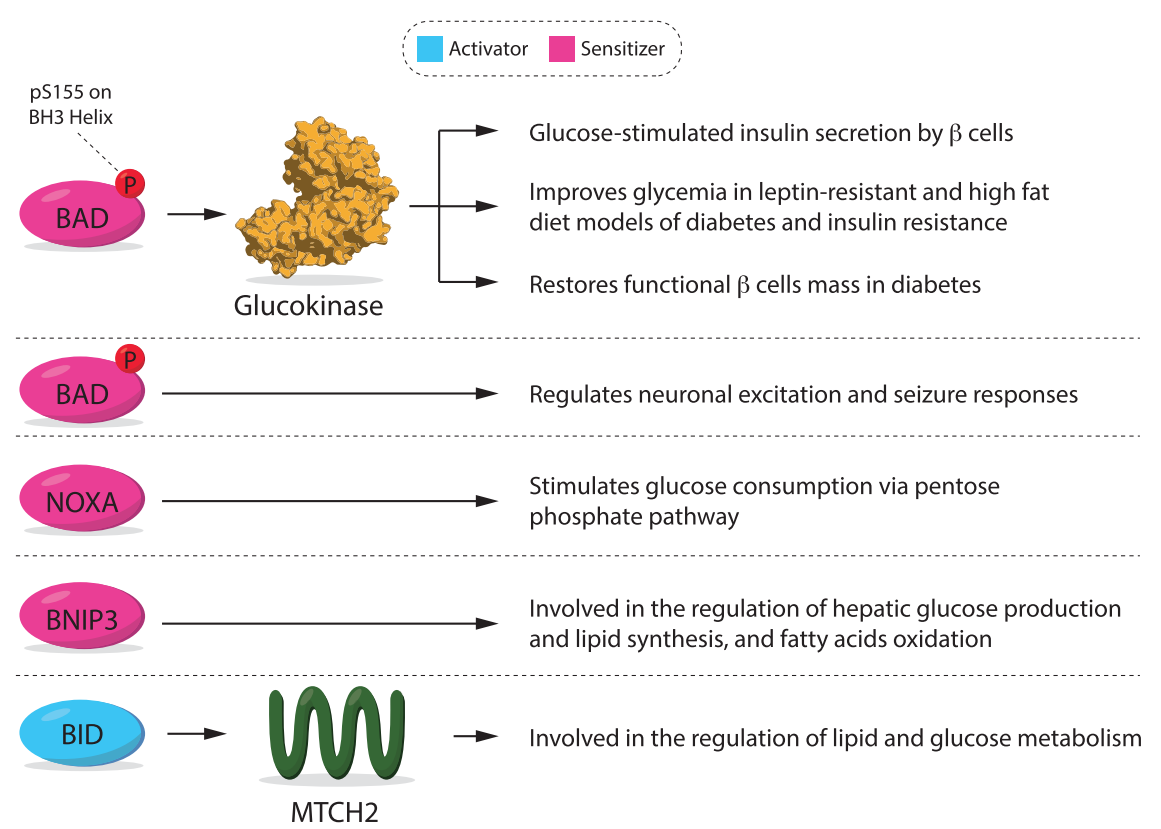

Figure 5 BCL-2 family members that regulate glucose and lipid metabolism. Both activator and sensitizer BH3-only BCL-2 family members participate in glucose metabolism. Whereas BAD and NOXA stimulate glucose consumption (although through different pathways), BNIP3 supports increased glucose production. BNIP3 and BID (potentially via MTCH2) also regulate lipid metabolism

capacity. ${ }^{64,65}$ BCL-2 also enhances XBP-1 splicing, although this does not appear to be through direct binding of BCL-2 to IRE $1 a{ }^{66}$ Finally, BIM and PUMA also bind IRE $1 a$ and regulate the splicing of XBP-1, ${ }^{67}$ although these findings have not been universally identified. ${ }^{68}$ Similar to their function as a rheostat for apoptosis, BCL-2 family members may act as a stress rheostat to modulate the kinetics and magnitude of adaptive responses through the UPR.

PERK dimerization and activation leads to the phosphorylation of elongation initiation factor $2 a$ (elF2a) that turns off global translation of new proteins, but also activates a select few proteins including activating transcription factor 4 (ATF4) ${ }^{69}$ (Figure 4, left panel). ATF4 activates the expression of several genes, including the transcription factor C/EBP homologous protein (CHOP) ${ }^{69} \mathrm{CHOP}$ promotes apoptosis through repression of BCL-2 and activation of BIM and PUMA. ${ }^{70,71}$ Loss of BAX and BAK attenuates ATF4 and CHOP activation, either through the PERK arm or by a crossover effect from the IRE1a arm. ${ }^{66}$ Two different groups have also identified a role for BOK in the PERK pathway, although with some distinction in its activity. ${ }^{47,72}$ Carpio et al. ${ }^{72}$ showed that BOK-null cells exhibit a diminished UPR and apoptotic response to several ER stress agents, including bortezomib (a proteasome inhibitor) and thapsigargin (a SERCA inhibitor). Although PERK and elF2 $a$ were activated in the BOK-null cells, ATF4 and CHOP expression were greatly diminished. Two different Bok $\mathrm{Bo}^{-/}$ mouse models did not show resistance to the ER stress agent thapsigargin, ${ }^{47,73}$ but one of the two studies showed that enforced BOK expression killed cells under proteasome inhibition. $^{47}$ Moreover, PERK inhibition resulted in BOKdependent cell death in response to the ER stress agent Tunicamycin (an inhibitor of N-glycosylation). ${ }^{47}$ In this setting, it was demonstrated that PERK inhibition resulted in loss of
ERAD degradation of BOK that was then available to kill in response to the ER stress agent. Thus, two studies have implicated that under ER stress, the combination of BOK loss and PERK pathway inhibition is protective. ${ }^{47,72}$ Taken together, two of the three arms of the UPR (IRE1 and PERK/ CHOP) appear to be modulated by BCL-2 family members before irreversible cell damage, with the apparent aim of an adaptive response.

\section{Regulation of Glucose and Lipid Metabolism}

Mitochondria are the cellular hubs for metabolism and thus it was tempting to speculate that BCL-2 family proteins regulators of life and death decisions - also possess nonapoptotic roles related to regulation of metabolism. The Danial group has clearly spearheaded this research direction by initially demonstrating (together with Stan Korsmeyer) that $\mathrm{BH} 3-$ only $\mathrm{BAD}$ resides in a glucokinase-containing complex that regulates glucose-driven mitochondrial respiration. ${ }^{74}$ Next, using a BAD BH3 peptide that targets glucokinase, it was demonstrated that BAD possesses a physiologic role in glucose-stimulated insulin secretion by $\beta$ cells $^{75}$ (Figure 5). Moreover, BAD phosphomimic variants improve glycemia in leptin-resistant and high-fat diet models of diabetes and insulin resistant, ${ }^{76}$ and restore functional $\beta$ cell mass in diabetes. ${ }^{77}$ The metabolic role of BAD is also relevant to the nervous system and is critical for regulating neuronal excitation and seizure responses. ${ }^{78}$

Thus, BAD is clearly the most investigated BCL-2 family member involved in glucose metabolism; ${ }^{79}$ however, there were additional members that were studied in this context. BH3-only NOXA was demonstrated to stimulate glucose consumption and seems to enhance glucose turnover via 


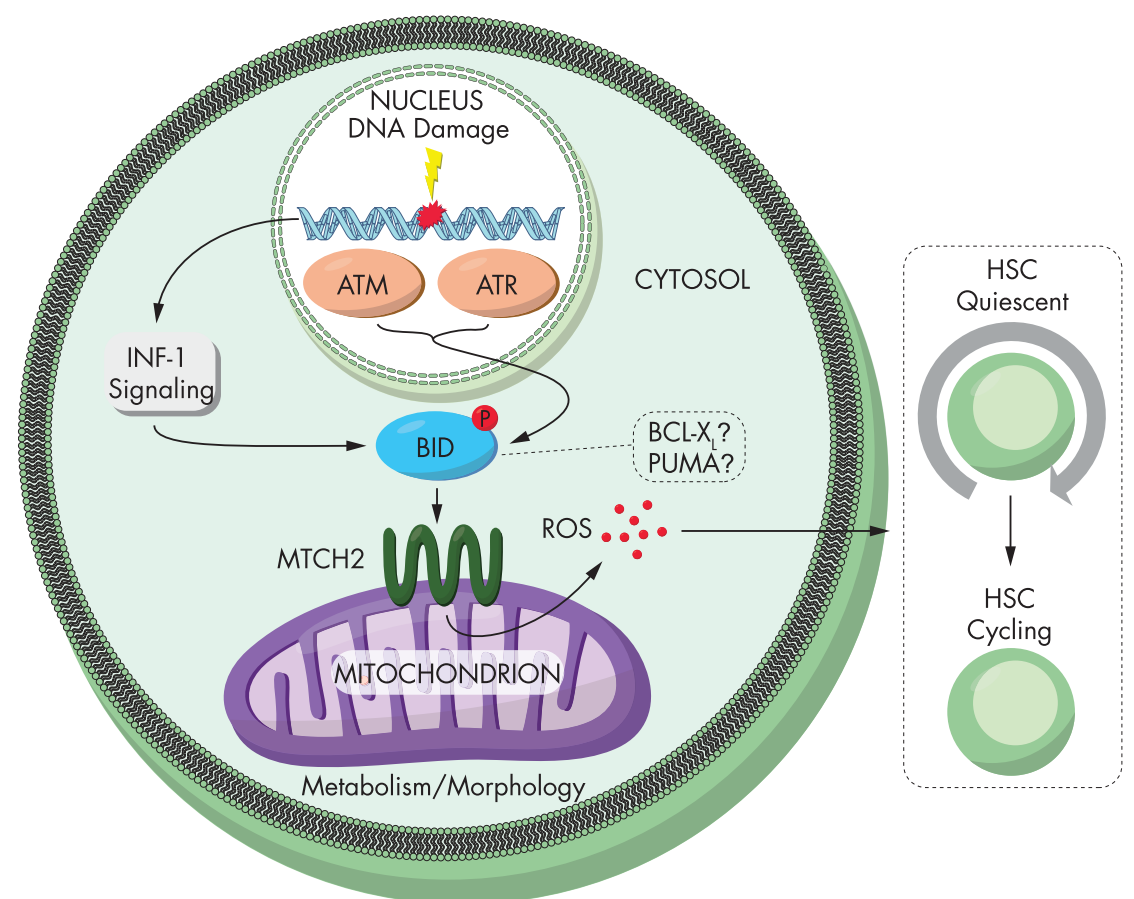

Figure 6 Regulation of hematopoietic stem cell (HSC) cycling by BCL-2 family members. BID, and potentially BCL-X and PUMA, shuttle from the nucleus to transmit the DNA damage response to regulate mitochondrial morphology and metabolism (including production of reactive oxygen species (ROS)) that regulate cycling of HSCs

the pentose phosphate pathway rather than through glycolysis. $^{80}$ On the other hand, BH3-only BNIP3, demonstrated to be involved in mitophagy, ${ }^{81,82}$ was also shown to be involved in lipid metabolism. Knockout of BNIP3 results in increased hepatic lipid synthesis in the liver, reduced fatty acid oxidation (FAO), and failure to augment hepatic glucose production during fasting. ${ }^{83}$ In addition, BH3-only BID was shown to be involved in lipid metabolism, demonstrating that truncated tBID inhibits FAO via inhibition of carnitine palmitoyltransferase-1 (CPT-1). ${ }^{84}$ In this respect, it is interesting to mention that mice deficient for muscle $\mathrm{MTCH} 2$ (BID receptor) are protected from diet-induced obesity and hyperinsulinemia, and demonstrate increased energy expenditure. ${ }^{9}$ Deletion of muscle MTCH2 also increases mitochondrial oxidative phosphorylation (OXPHOS) and mass, triggers conversion from glycolytic to oxidative fibers, increases capacity for endurance exercise, and increases heart function. Moreover, metabolic profiling of mice deficient for muscle $\mathrm{MTCH} 2$ reveals preference to carbohydrate utilization, and an increase in mitochondria TCA cycle activity and glycolytic flux in muscles. ${ }^{9}$ On the other hand, overexpression of $\mathrm{MTCH} 2$ leads to the development of fatty livers and kidneys. ${ }^{85}$ Thus, several $\mathrm{BH} 3-$ only proteins affect lipid and glucose metabolism, but their exact mechanisms of action still need to be revealed.

\section{Regulation of Macroautophagy and Mitophagy}

Macroautophagy (henceforth autophagy) is a core metabolic process for recycling and biogenesis that initiates at the ER and $\mathrm{OMM}$ and ends with the release of the recycled macromolecules into the cytosol. Under conditions of nutrient starvation, a double-membrane structure forms at sites designated by the initiation complex that includes Beclin-1. ${ }^{86}$ Beclin-1, the mammalian ortholog of yeast Atg6, has a functional $\mathrm{BH} 3$ domain. ${ }^{87}$ Therefore, BCL-2, BCL- $\mathrm{X}_{\mathrm{L}}, \mathrm{BCL}-\mathrm{W}$, and $M C L-1$ all bind Beclin-1, prevent it from forming the initiation complex, and inhibit autophagy. ${ }^{87,88}$ The Beclin-1/ BCL-2 interaction is stabilized by NAF-1, ${ }^{89}$ and phosphorylation of the Beclin-1 BH3 domain by Mst1, ${ }^{90}$ but disrupted by phosphorylation of BCL-2 by JNK1. ${ }^{91}$ In fact, mice with a BCL-2 that cannot be phosphorylated by JNK1 have increased affinity to Beclin-1 and deficient exercise- or starvation-induced autophagy with a decrease in endurance and altered glucose metabolism. ${ }^{92}$ The presence of a metabolic defect in these BCL-2 mutant mice strongly supports BCL-2 alternative function in autophagy.

BH3-only proteins (e.g., BAD, BIK, BNIP3, and NOXA) and BH3 mimetics (e.g., ABT-737) affect autophagy by disrupting the anti-apoptotic-Beclin-1 complex. ${ }^{87,93}$ The importance of $\mathrm{BH} 3-$ only proteins in autophagy is conserved in C. elegans where gain-of-function EGL1 mutations increase autophagy and deletions of EGL1 impair autophagy. ${ }^{87}$ In contrast to the pro-autophagic role ascribed to most $\mathrm{BH} 3$-only proteins in freeing Beclin-1 from the inhibitory anti-apoptotic complex, BIM inhibits autophagy by directly binding Beclin-1 and sequestering it to dynein light chains. ${ }^{94}$ In response to nutrient starvation, JNK phosphorylates BIM and Beclin-1 is released to initiate autophagy. The difference between BIM and other $\mathrm{BH} 3-$ only proteins in regulating autophagy through Beclin-1 may have implications on the manner by which the cell balances apoptosis with autophagy.

BCL-2 family members also function in the selective autophagic removal of dysfunctional mitochondria, known as 


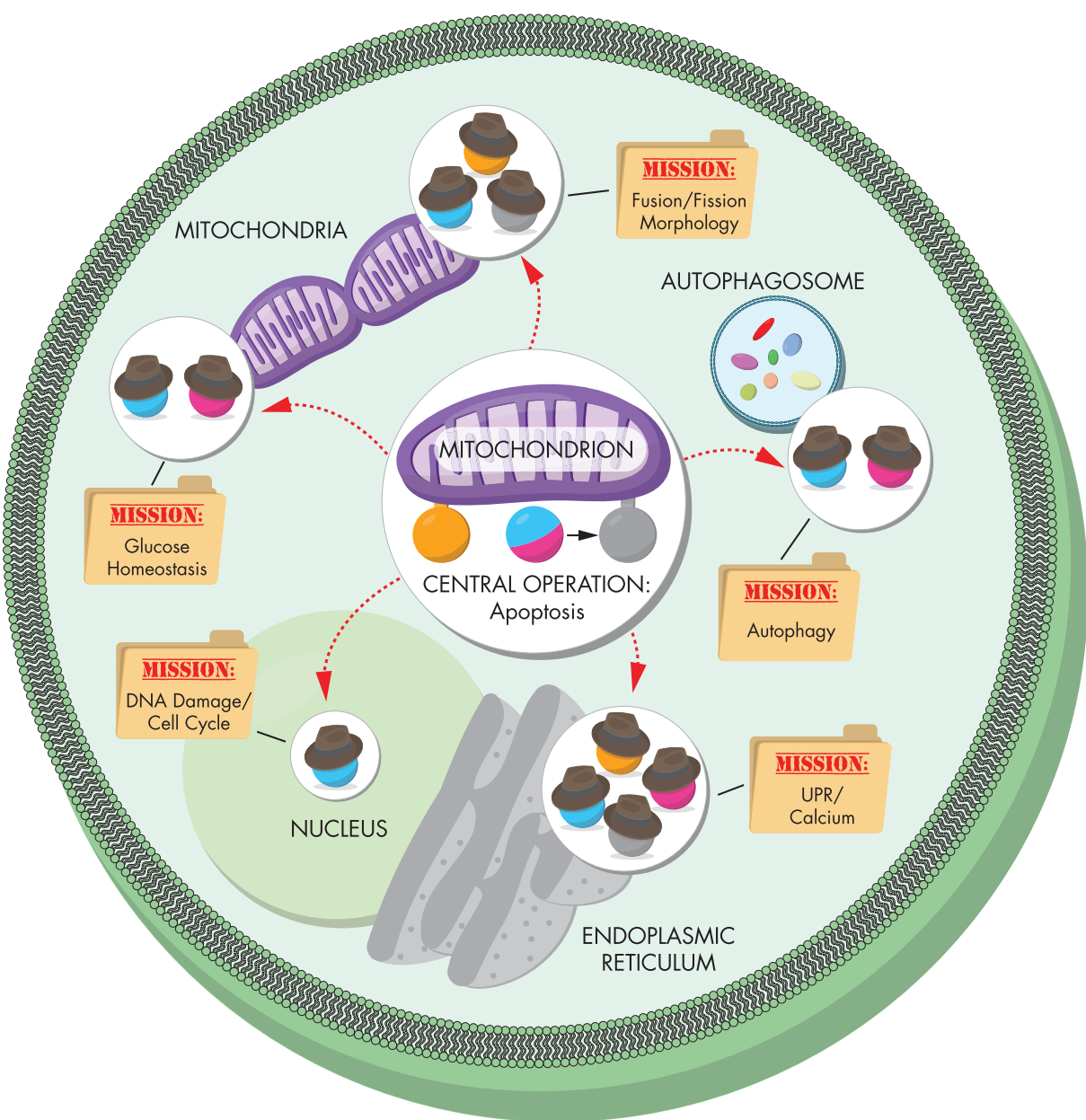

Figure 7 Conceptualization of BCL-2 family members as spies throughout the cell. Various BCL-2 family members have missions to participate in 'day jobs' throughout the cell and contribute to the cell's ability to function. How that mission proceeds determines if they need to report back and participate in their 'night job' function in the intrinsic pathway of apoptosis at the mitochondrion

mitophagy. In response to starvation and hypoxia, BNIP3 and NIX (BNIP3L) are transcriptionally activated by HIF-1 $a$ and mediate mitophagy. ${ }^{95}$ BNIP3 promotes mitophagy (and ERphagy) predominantly by acting as a receptor for LC3-II, a proteolipid component of the elongating autophagosome. ${ }^{96} \mathrm{In}$ addition, BNIP3 inhibits the cleavage and inactivation of PINK1, a mitochondrial kinase that recruits and activates PARKIN, an ubiquitin E3-ligase for multiple proteins on the mitochondria. ${ }^{97}$ NIX has also been shown to promote mitophagy by acting as a receptor for LC3 proteins $^{98}$ and recruitment of PARKIN by regulating mitochondrial membrane potential. ${ }^{99,100}$ Physiologically, NIX is required for mitochondrial clearance during erythroid maturation. ${ }^{100}$ Mitophagy is inhibited by the anti-apoptotic BCL-2 proteins that bind and prevent the translocation of PARKIN. ${ }^{101}$ This function can be neutralized by BH3-only proteins, BAD, BIM, NOXA, and PUMA, as well as a BH3-mimetic. ${ }^{101}$ Taken together, pro-apoptotic signaling also stimulates mitophagy that might serve as a protective mechanism from loss of mitochondrial function and occur as an adaptive response before the need for apoptosis.

\section{Regulation of the DNA Damage Response}

In eukaryotes, each cell's genetic material is constantly subjected to DNA damage. Following DNA damage, the cell may activate a survival system that enables repair and continuation of its normal life cycle, or it may activate its apoptotic machinery in the face of extensive or irreparable damage.$^{102}$ One of the major responses associated with the cell survival network is the temporary arrest of cell cycle progression that reflects the activation of cell cycle checkpoints. ${ }^{103,104}$ A prototype transducer of the DNA damage response (DDR) is the ATM kinase, a nuclear serine-threonine protein kinase. ${ }^{105}$ Activated ATM phosphorylates a wide spectrum of substrates, and the Gross and Korsmeyer groups identified BID as one of these substrates.

DNA damage leads to rapid phosphorylation of BID by the ATM kinase on serines 61 and 78, and expression of a non-phosphorylatable BID mutant $\left(B I D^{S 61 A / S 78 A}\right.$ or $\left.B I D^{A A}\right)$ results in a cell-cycle arrest defect and an increase in apoptosis. ${ }^{106,107}$ These findings together with additional results demonstrating that BID shuttles between the nucleus and mitochondria ${ }^{108}$ are consistent with the idea that BID 
functions as a cellular sentinel of DNA damage (Figure 6). Moreover, the Gross group went on to show that $B I D^{A A}$ knockin mice are hypersensitive to whole-body irradiation because of premature entry of HSCs into cycle and increased levels of HSC apoptosis. ${ }^{109}$ In addition, loss of BID phosphorylation is associated with accumulation of BID at the mitochondria resulting in elevated levels of mitochondrial reactive oxygen species (ROS), suggesting that basal phosphorylation of BID is critical for balancing mitochondrial ROS thus regulating HSC quiescence. ${ }^{110}$ More recently, it was demonstrated that $\mathrm{MTCH} 2$ (BID receptor ${ }^{8}$ ) is the regulator of mitochondrial ROS/ metabolism in the ATM-BID pathway in HSCs. ${ }^{10}$ Loss of $\mathrm{MTCH} 2$ increases mitochondrial OXPHOS, triggering HSC and progenitor entry into cycle. Elevated OXPHOS was accompanied by an increase in mitochondrial size, increase in ATP and ROS levels, and protection from irradiation-induced apoptosis. In contrast, BID ${ }^{\mathrm{AA}}$ induced a similar increase in OXPHOS, but with higher ROS and reduced ATP levels, and was associated with hypersensitivity to irradiation. ${ }^{10}$ Thus, $\mathrm{MTCH} 2$ is a negative regulator of mitochondrial OXPHOS downstream of BID, indispensable in maintaining HSC homeostasis.

A recent study further confirms the above findings, demonstrating that BID is a critical regulator of DNA damage-induced mitochondrial ROS in the interferon (IFN-1) signaling pathway in HSCs. ${ }^{111}$ Importantly, in a series of elegant studies, the Zinkel group ${ }^{112,113}$ demonstrated that BID mediates the DDR to replicative stress directed by the ATM and Rad3-related (ATR) kinase. In the initial studies it was found that BID is part of the DNA damage sensor complex (ATR/ATRIP/RPA) acting to amplify the ATR-directed cellular response to replicative DNA damage. Later, the relevance of these findings to the in vivo setting was demonstrated by showing that BID plays a critical role in protecting HSCs following chronic replicative stress ${ }^{114}$ and delays T-cell leukemogenesis in $A T M^{-1-}$ mice. ${ }^{115}$ All these studies together resolved an old controversy over whether BID plays a role in the DDR. ${ }^{116}$

Although BID is clearly the most investigated BCL-2 family member in the non-apoptotic arm of the DDR, ${ }^{117}$ two additional members were studied in this context. The first study showed that ectopic expression of BCL- $X_{L}$ in human cells enhances homology-directed repair (HDR) of DNA double-strand breaks (DSBs), ${ }^{118}$ suggesting that $B C L-X_{L}$ is actively involved in DNA repair. The second study showed that Puma $^{-1-}$ HSCs spared from radiation can be better maintained in a quiescent state, and can be induced to more efficient DNA repair, ${ }^{119}$ suggesting that PUMA is possibly involved in triggering $\mathrm{HSC}$ exit from quiescence and inhibiting DNA repair.

\section{Conclusions: BCL-2 Family Proteins as Regulators of Numerous Cellular Functions}

It has taken over 30 years to elucidate the regulation of apoptosis by an elegant network of interacting BCL-2 family proteins. Our understanding of the complicated relative binding affinities and dynamic structural transformations has led to the development of small molecules that can selectively and specifically manipulate the primed state of a cell nudging it ever closer to death. However, during this first phase of our exploration we have seen multiple places where BCL-2 family members function beyond their canonical role in apoptosis. These alternative roles place BCL-2 family members throughout the cell, including the OMM, the IMM, the ER, the cytosol, and the nucleus. Many of these pathways (e.g., autophagy, electron transport chain, and gluconeogenesis) are essential for cell survival by regulating nutrient and energy metabolism, whereas others (e.g., UPR and DDR) provide critical respites that help a cell undergo repair before deciding whether the damage is beyond reproach and the cell needs to commit suicide. As such, one might view BCL-2 family members as 'sleeper agents' ready to inform on the state of the cell in their clandestine, night job as an agent of cell death (Figure 7). However, it is important to emphasize that the most effective sleeper agents integrate seamlessly into daily life and functions. Over time, their informant function that ties into apoptosis might become secondary to functions in cellular signaling. Deciphering how BCL-2 family members integrate into the broader cellular context over the next 30 years will likely yield further rich and sophisticated signaling networks that can be targeted within disease states.

\section{Conflict of Interest}

The authors declare no conflict of interest.

Acknowledgements. We thank E Smith for computer graphics assistance. AG is supported in part by the Israel Science Foundation (ISF) and the Canada-Israel Joint Program (CIHR/IDRC/ISF/Azrieli). AG is the incumbent of the Marketa and Frederick Alexander Professorial Chair. SGK is supported by grants from the NIH (1R21CA198561, 1R01HL131793), Connecticut Innovations, March of Dimes, Alliance for Cancer Gene Therapy (ACGT), and Gabrielle's Angel Foundation.

1. Martinou JC, Youle RJ. Mitochondria in apoptosis: Bcl-2 family members and mitochondrial dynamics. Dev Cell 2011; 21: 92-101.

2. Borner $\mathrm{C}$, Andrews DW. The apoptotic pore on mitochondria: are we breaking through or still stuck? Cell Death Differ 2014; 21: 187-191.

3. Frank S, Gaume B, Bergmann-Leitner ES, Leitner WW, Robert EG, Catez F et al. The role of dynamin-related protein 1, a mediator of mitochondrial fission, in apoptosis. Dev Cell 2001; 1 : 515-525.

4. Youle RJ, Karbowski M. Mitochondrial fission in apoptosis. Nat Rev Mol Cell Biol 2005; 6: 657-663.

5. Karbowski M, Norris KL, Cleland MM, Jeong SY, Youle RJ. Role of Bax and Bak in mitochondrial morphogenesis. Nature 2006; 443: 658-662.

6. Brooks $C$, Wei $Q$, Feng $L$, Dong $G$, Tao $Y$, Mei $L$ et al. Bak regulates mitochondrial morphology and pathology during apoptosis by interacting with mitofusins. Proc Natl Acad Sci USA 2007; 104: 11649-11654.

7. Hoppins S, Edlich F, Cleland MM, Banerjee S, McCaffery JM, Youle RJ et al. The soluble form of Bax regulates mitochondrial fusion via MFN2 homotypic complexes. Mol Cell 2011; 41: $150-160$.

8. Zaltsman Y, Shachnai L, Yivgi-Ohana N, Schwarz M, Maryanovich M, Houtkooper RH et al. MTCH2/MIMP is a major facilitator of tBID recruitment to mitochondria. Nat Cell Biol 2010; 12: $553-562$.

9. Buzaglo-Azriel L, Kuperman Y, Tsoory M, Zaltsman Y, Shachnai L, Zaidman SL et al. Loss of muscle MTCH2 increases whole-body energy utilization and protects from diet-induced obesity. Cell Rep 2016; 14: 1602-1610.

10. Maryanovich M, Zaltsman Y, Ruggiero A, Goldman A, Shachnai L, Zaidman SL et al. An MTCH2 pathway repressing mitochondria metabolism regulates haematopoietic stem cell fate. Nat Commun 2015; 6: 7901.

11. Berman SB, Chen YB, Qi B, McCaffery JM, Rucker EB 3rd, Goebbels S et al. Bcl-xL increases mitochondrial fission, fusion, and biomass in neurons. J Cell Biol 2009; 184: 707-719.

12. Li H, Alavian KN, Lazrove E, Mehta N, Jones A, Zhang $P$ et al. A Bcl-xL-Drp1 complex regulates synaptic vesicle membrane dynamics during endocytosis. Nat Cell Biol 2013; 15: 773-785.

13. Cleland MM, Norris KL, Karbowski M, Wang C, Suen DF, Jiao S et al. Bcl-2 family interaction with the mitochondrial morphogenesis machinery. Cell Death Differ 2011; 18: 235-247. 
14. Delivani P, Adrain C, Taylor RC, Duriez PJ, Martin SJ. Role for CED-9 and Egl-1 as regulators of mitochondrial fission and fusion dynamics. Mol Cell 2006; 21: 761-773.

15. Rolland SG, Lu Y, David CN, Conradt B. The BCL-2-like protein CED-9 of C. elegans promotes FZO-1/Mfn1,2- and EAT-3/Opa1-dependent mitochondrial fusion. J Cell Biol 2009; 186: 525-540.

16. Tanner EA, Blute TA, Brachmann CB, McCall K. Bcl-2 proteins and autophagy regulate mitochondrial dynamics during programmed cell death in the Drosophila ovary. Development 2011; 138: 327-338.

17. Bernardi $P$, Rasola A, Forte M, Lippe $G$. The mitochondrial permeability transition pore: channel formation by F-ATP synthase, integration in signal transduction, and role in pathophysiology. Physiol Rev 2015; 95: 1111-1155.

18. Marzo I, Brenner C, Zamzami N, Jurgensmeier JM, Susin SA, Vieira HL et al. Bax and adenine nucleotide translocator cooperate in the mitochondrial control of apoptosis. Science 1998; 281: 2027-2031.

19. Shimizu S, Narita M, Tsujimoto Y. Bcl-2 family proteins regulate the release of apoptogenic cytochrome $\mathrm{c}$ by the mitochondrial channel VDAC [see comments]. Nature 1999; 399 : 483-487.

20. Kokoszka JE, Waymire KG, Levy SE, Sligh JE, Cai J, Jones DP et al. The ADP/ATP translocator is not essential for the mitochondrial permeability transition pore. Nature 2004; 427: 461-465.

21. Baines CP, Kaiser RA, Sheiko T, Craigen WJ, Molkentin JD. Voltage-dependent anion channels are dispensable for mitochondrial-dependent cell death. Nat Cell Biol 2007; 9: 550-555.

22. Whelan RS, Konstantinidis $K$, Wei $A C$, Chen $Y$, Reyna DE, Jha S et al. Bax regulates primary necrosis through mitochondrial dynamics. Proc Natl Acad Sci USA 2012; 109: 6566-6571.

23. Karch J, Kwong JQ, Burr AR, Sargent MA, Elrod JW, Peixoto PM et al. Bax and Bak function as the outer membrane component of the mitochondrial permeability pore in regulating necrotic cell death in mice. Elife 2013; 2: e00772.

24. Hockenbery D, Nunez G, Milliman C, Schreiber RD, Korsmeyer SJ. Bcl-2 is an inner mitochondrial membrane protein that blocks programmed cell death. Nature 1990; $\mathbf{3 4 8}$ 334-336

25. Nguyen M, Millar DG, Yong VW, Korsmeyer SJ, Shore GC. Targeting of Bcl-2 to the mitochondrial outer membrane by a $\mathrm{COOH}$-terminal signal anchor sequence. $\mathrm{J}$ Biol $\mathrm{Chem}$ 1993; 268: 25265-25268.

26. Gotow T, Shibata M, Kanamori S, Tokuno O, Ohsawa Y, Sato N et al. Selective localization of $\mathrm{Bcl}-2$ to the inner mitochondrial and smooth endoplasmic reticulum membranes in mammalian cells. Cell Death Differ 2000; 7: 666-674.

27. Chen ZX, Pervaiz S. Involvement of cytochrome $\mathrm{c}$ oxidase subunits $\mathrm{Va}$ and $\mathrm{Vb}$ in the regulation of cancer cell metabolism by Bcl-2. Cell Death Differ 2010; 17: 408-420.

28. Eliseev RA, Malecki J, Lester T, Zhang Y, Humphrey J, Gunter TE. Cyclophilin D interacts with Bcl2 and exerts an anti-apoptotic effect. J Biol Chem 2009; 284: 9692-9699.

29. Alavian KN, Li H, Collis L, Bonanni L, Zeng L, Sacchetti S et al. Bcl-xL regulates metabolic efficiency of neurons through interaction with the mitochondrial F1FO ATP synthase. Nat Cell Biol 2011; 13: 1224-1233.

30. Fannjiang $\mathrm{Y}, \mathrm{Kim} \mathrm{CH}$, Huganir RL, Zou S, Lindsten T, Thompson $\mathrm{CB}$ et al. BAK alters neuronal excitability and can switch from anti- to pro-death function during postnatal development. Dev Cell 2003; 4: 575-585.

31. Perciavalle RM, Stewart DP, Koss B, Lynch J, Milasta S, Bathina M et al. Anti-apoptotic MCL-1 localizes to the mitochondrial matrix and couples mitochondrial fusion to respiration. Nat Cell Biol 2012; 14: 575-583.

32. Wang X, Bathina M, Lynch J, Koss B, Calabrese C, Frase S et al. Deletion of MCL-1 causes lethal cardiac failure and mitochondrial dysfunction. Genes Dev 2013; 27: 1351-1364.

33. Berridge MJ, Lipp P, Bootman MD. The versatility and universality of calcium signalling. Nat Rev Mol Cell Biol 2000; 1: 11-21.

34. Eckenrode EF, Yang J, Velmurugan GV, Foskett JK, White C. Apoptosis protection by Mcl-1 and $\mathrm{Bcl}-2$ modulation of inositol 1,4,5-trisphosphate receptor-dependent $\mathrm{Ca} 2+$ signaling $J$ Biol Chem 2010; 285: 13678-13684.

35. White C, Li C, Yang J, Petrenko NB, Madesh M, Thompson CB et al. The endoplasmic reticulum gateway to apoptosis by $\mathrm{Bcl}-\mathrm{X}(\mathrm{L})$ modulation of the InsP3R. Nat Cell Biol 2005; 7: 1021-1028.

36. Rong YP, Aromolaran AS, Bultynck G, Zhong F, Li X, McColl K et al. Targeting Bcl-2-IP3 receptor interaction to reverse Bcl-2's inhibition of apoptotic calcium signals. Mol Cell 2008; 31: 255-265.

37. Bonneau B, Nougarede A, Prudent J, Popgeorgiev N, Peyrieras N, Rimokh R et al. The Bcl-2 homolog Nrz inhibits binding of IP3 to its receptor to control calcium signaling during zebrafish epiboly. Sci Signal 2014; 7: ra14.

38. Dremina ES, Sharov VS, Kumar K, Zaidi A, Michaelis EK, Schoneich C. Anti-apoptotic protein $\mathrm{Bcl}-2$ interacts with and destabilizes the sarcoplasmic/endoplasmic reticulum $\mathrm{Ca} 2$ +-ATPase (SERCA). Biochem J 2004; 383(Pt 2): 361-370.

39. Vanden Abeele F, Skryma R, Shuba Y, Van Coppenolle F, Slomianny C, Roudbaraki M et al. $\mathrm{Bcl}-2$-dependent modulation of $\mathrm{Ca}(2+)$ homeostasis and store-operated channels in prostate cancer cells. Cancer Cell 2002; 1: 169-179.

40. Ferdek PE, Gerasimenko JV, Peng S, Tepikin AV, Petersen OH, Gerasimenko OV. A novel role for Bcl-2 in regulation of cellular calcium extrusion. Curr Biol 2012; 22: 1241-1246.

41. Schulman JJ, Wright FA, Kaufmann T, Wojcikiewicz RJ. The Bcl-2 protein family member Bok binds to the coupling domain of inositol 1,4,5-trisphosphate receptors and protects them from proteolytic cleavage. J Biol Chem 2013; 288: 25340-25349.
42. Scorrano L, Oakes SA, Opferman JT, Cheng EH, Sorcinelli MD, Pozzan T et al. BAX and BAK regulation of endoplasmic reticulum Ca2+: a control point for apoptosis. Science 2003; 300: 135-139.

43. Oakes SA, Scorrano L, Opferman JT, Bassik MC, Nishino M, Pozzan T et al. Proapoptotic $\mathrm{BAX}$ and BAK regulate the type 1 inositol trisphosphate receptor and calcium leak from the endoplasmic reticulum. Proc Natl Acad Sci USA 2005; 102: 105-110.

44. Diwan A, Matkovich SJ, Yuan Q, Zhao W, Yatani A, Brown JH et al. Endoplasmic reticulum mitochondria crosstalk in NIX-mediated murine cell death. J Clin Invest 2009; 119 203-212.

45. Luo X, He Q, Huang Y, Sheikh MS. Transcriptional upregulation of PUMA modulates endoplasmic reticulum calcium pool depletion-induced apoptosis via Bax activation. Cell Death Differ 2005; 12: 1310-1318.

46. Mathai JP, Germain M, Shore GC. BH3-only BIK regulates BAX,BAK-dependent release of $\mathrm{Ca} 2+$ from endoplasmic reticulum stores and mitochondrial apoptosis during stressinduced cell death. J Biol Chem 2005; 280: 23829-23836.

47. Llambi F, Wang YM, Victor B, Yang M, Schneider DM, Gingras $S$ et al. BOK is a non-canonical BCL-2 family effector of apoptosis regulated by ER-associated degradation. Cell 2016; 165: 421-433.

48. Schulman JJ, Wright FA, Han X, Zluhan EJ, Szczesniak LM, Wojcikiewicz RJ. The stability and expression level of Bok are governed by binding to inositol 1,4,5-trisphosphate receptors. J Biol Chem 2016; 291: 11820-11828.

49. D'Orsi B, Engel T, Pfeiffer S, Nandi S, Kaufmann T, Henshall DC et al. Bok is not pro-apoptotic but suppresses poly ADP-ribose polymerase-dependent cell death pathways and protects against excitotoxic and seizure-induced neuronal injury. J Neurosci 2016; 36 : 4564-4578.

50. Brady HJ, Gil-Gomez G, Kirberg J, Berns AJ. Bax alpha perturbs T cell development and affects cell cycle entry of T cells. EMBO J 1996; 15: 6991-7001.

51. O'Reilly LA, Huang DC, Strasser A. The cell death inhibitor Bcl-2 and its homologues influence control of cell cycle entry. EMBO J 1996; 15: 6979-6990.

52. Huang DC, O'Reilly LA, Strasser A, Cory S. The anti-apoptosis function of Bcl-2 can be genetically separated from its inhibitory effect on cell cycle entry. EMBO J 1997; 16: 4628-4638.

53. Choi J, Choi K, Benveniste EN, Rho SB, Hong YS, Lee JH et al. Bcl-2 promotes invasion and lung metastasis by inducing matrix metalloproteinase-2. Cancer Res 2005; 65: 5554-5560.

54. Jones RG, Bui T, White C, Madesh M, Krawczyk CM, Lindsten T et al. The proapoptotic factors Bax and Bak regulate $\mathrm{T}$ Cell proliferation through control of endoplasmic reticulum $\mathrm{Ca}(2+)$ homeostasis. Immunity 2007; 27: 268-280.

55. Ludwinski MW, Sun J, Hilliard B, Gong S, Xue F, Carmody RJ et al. Critical roles of Bim in T cell activation and T cell-mediated autoimmune inflammation in mice. J Clin Invest 2009; 119: $1706-1713$.

56. Chen DF, Schneider GE, Martinou JC, Tonegawa S. Bcl-2 promotes regeneration of severed axons in mammalian CNS. Nature 1997; 385: 434-439.

57. Jiao J, Huang X, Feit-Leithman RA, Neve RL, Snider W, Dartt DA et al. Bcl-2 enhances Ca (2+) signaling to support the intrinsic regenerative capacity of CNS axons. EMBO J 2005; 24: $1068-1078$.

58. Machado-Vieira R, Pivovarova NB, Stanika RI, Yuan P, Wang Y, Zhou R et al. The Bcl-2 gene polymorphism rs956572AA increases inositol 1,4,5-trisphosphate receptor-mediated endoplasmic reticulum calcium release in subjects with bipolar disorder. Biol Psychiatry 2011; 69: 344-352.

59. Iurlaro R, Munoz-Pinedo C. Cell death induced by endoplasmic reticulum stress. FEBS J 2016; 283: 2640-2652

60. Yamamoto $\mathrm{K}$, Ichijo $\mathrm{H}$, Korsmeyer SJ. BCL-2 is phosphorylated and inactivated by an ASK1/Jun N-terminal protein kinase pathway normally activated at G(2)/M. Mol Cell Biol 1999; 19: 8469-8478.

61. Urano F, Wang X, Bertolotti A, Zhang Y, Chung P, Harding HP et al. Coupling of stress in the ER to activation of JNK protein kinases by transmembrane protein kinase IRE1. Science 2000; 287: 664-666.

62. Hetz C, Bernasconi P, Fisher J, Lee AH, Bassik MC, Antonsson B et al. Proapoptotic BAX and BAK modulate the unfolded protein response by a direct interaction with IRE1alpha. Science 2006; 312: 572-576.

63. Hollien J, Weissman JS. Decay of endoplasmic reticulum-localized mRNAs during the unfolded protein response. Science 2006; 313: 104-107.

64. Calfon M, Zeng $\mathrm{H}$, Urano $\mathrm{F}$, Till $\mathrm{JH}$, Hubbard SR, Harding HP et al. IRE1 couples endoplasmic reticulum load to secretory capacity by processing the XBP-1 mRNA. Nature 2002: 415: 92-96.

65. Yoshida H, Matsui T, Yamamoto A, Okada T, Mori K. XBP1 mRNA is induced by ATF6 and spliced by IRE1 in response to ER stress to produce a highly active transcription factor. Cell 2001; 107: 881-891.

66. Chonghaile TN, Gupta S, John M, Szegezdi E, Logue SE, Samali A. BCL-2 modulates the unfolded protein response by enhancing splicing of $\mathrm{X}$-box binding protein-1. Biochem Biophys Res Commun 2015; 466: 40-45.

67. Rodriguez DA, Zamorano S, Lisbona F, Rojas-Rivera D, Urra H, Cubillos-Ruiz JR et al. $\mathrm{BH} 3-o n l y$ proteins are part of a regulatory network that control the sustained signalling of the unfolded protein response sensor IRE1alpha. EMBO J 2012; 31: 2322-2335.

68. Herold MJ, O'Reilly LA, Lin A, Srivastava R, Doerflinger M, Bouillet $P$ et al. Evidence against upstream regulation of the unfolded protein response (UPR) by pro-apoptotic BIM and PUMA. Cell Death Dis 2014; 5: e1354. 
69. Harding HP, Novoa I, Zhang Y, Zeng H, Wek R, Schapira M et al. Regulated translation initiation controls stress-induced gene expression in mammalian cells. Mol Cell 2000; 6 : 1099-1108.

70. McCullough KD, Martindale JL, Klotz LO, Aw TY, Holbrook NJ. Gadd153 sensitizes cells to endoplasmic reticulum stress by down-regulating $\mathrm{Bcl} 2$ and perturbing the cellular redox state. Mol Cell Biol 2001; 21: 1249-1259.

71. Puthalakath $\mathrm{H}$, O'Reilly LA, Gunn P, Lee L, Kelly PN, Huntington ND et al. ER stress triggers apoptosis by activating BH3-only protein Bim. Cell 2007; 129: 1337-1349.

72. Carpio MA, Michaud M, Zhou W, Fisher JK, Walensky LD, Katz SG. BCL-2 family member BOK promotes apoptosis in response to endoplasmic reticulum stress. Proc Natl Acad Sci USA 2015; 112: 7201-7206.

73. Fernandez-Marrero Y, Ke F, Echeverry N, Bouillet P, Bachmann D, Strasser A et al. Is BOK required for apoptosis induced by endoplasmic reticulum stress? Proc Natl Acad Sci USA 2016; 113: E492-E493.

74. Danial NN, Gramm CF, Scorrano L, Zhang CY, Krauss S, Ranger AM et al. BAD and glucokinase reside in a mitochondrial complex that integrates glycolysis and apoptosis Nature 2003; 424: 952-956.

75. Danial NN, Walensky LD, Zhang CY, Choi CS, Fisher JK, Molina AJ et al. Dual role of proapoptotic BAD in insulin secretion and beta cell survival. Nat Med 2008; 14: 144-153.

76. Gimenez-Cassina A, Garcia-Haro L, Choi CS, Osundiji MA, Lane EA, Huang $\mathrm{H}$ et al. Regulation of hepatic energy metabolism and gluconeogenesis by BAD. Cell Metab 2014; 19: $272-284$

77. Ljubicic S, Polak K, Fu A, Wiwczar J, Szlyk B, Chang Y et al. Phospho-BAD BH3 mimicry protects beta cells and restores functional beta cell mass in diabetes. Cell Rep 2015; 10 497-504.

78. Gimenez-Cassina A, Martinez-Francois JR, Fisher JK, Szlyk B, Polak K, Wiwczar J et al. BAD-dependent regulation of fuel metabolism and K(ATP) channel activity confers resistance to epileptic seizures. Neuron 2012; 74: 719-730.

79. Gimenez-Cassina A, Danial NN. Regulation of mitochondrial nutrient and energy metabolism by BCL-2 family proteins. Trends Endocrinol Metab 2015; 26: 165-175.

80. Lowman XH, McDonnell MA, Kosloske A, Odumade OA, Jenness C, Karim CB et al. The proapoptotic function of Noxa in human leukemia cells is regulated by the kinase Cdk5 and by glucose. Mol Cell 2010; 40: 823-833.

81. Landes T, Emorine LJ, Courilleau D, Rojo M, Belenguer P, Arnaune-Pelloquin L. The $\mathrm{BH} 3$-only Bnip3 binds to the dynamin Opa1 to promote mitochondrial fragmentation and apoptosis by distinct mechanisms. EMBO Rep 2010; 11: 459-465.

82. Rikka S, Quinsay MN, Thomas RL, Kubli DA, Zhang X, Murphy AN et al. Bnip3 impairs mitochondrial bioenergetics and stimulates mitochondrial turnover. Cell Death Differ 2011; 18: $721-731$.

83. Glick D, Zhang W, Beaton M, Marsboom G, Gruber M, Simon MC et al. BNip3 regulates mitochondrial function and lipid metabolism in the liver. Mol Cell Biol 2012; 32: 2570-2584.

84. Giordano A, Calvani M, Petillo O, Grippo P, Tuccillo F, Melone MA et al. tBid induces alterations of mitochondrial fatty acid oxidation flux by malonyl-CoA-independent inhibition of carnitine palmitoyltransferase-1. Cell Death Differ 2005; 12: 603-613.

85. Bar-Lev Y, Moshitch-Moshkovitz S, Tsarfaty G, Kaufman D, Horev J, Resau JH et al. Mimp/ Mtch2, an obesity susceptibility gene, induces alteration of fatty acid metabolism in transgenic mice. PLOS ONE 2016; 11: e0157850.

86. Zeng X, Overmeyer JH, Maltese WA. Functional specificity of the mammalian Beclin-Vps34 PI 3-kinase complex in macroautophagy versus endocytosis and lysosomal enzyme trafficking. J Cell Sci 2006; 119(Pt 2): 259-270.

87. Maiuri MC, Le Toumelin G, Criollo A, Rain JC, Gautier F, Juin P et al. Functional and physical interaction between $\mathrm{BCl}-\mathrm{X}(\mathrm{L})$ and a BH3-like domain in Beclin-1. EMBO J 2007; 26 : 2527-2539.

88. Pattingre S, Tassa A, Qu X, Garuti R, Liang XH, Mizushima N et al. Bcl-2 antiapoptotic proteins inhibit Beclin 1-dependent autophagy. Cell 2005; 122: 927-939.

89. Chang NC, Nguyen M, Germain M, Shore GC. Antagonism of Beclin 1-dependent autophagy by BCL-2 at the endoplasmic reticulum requires NAF-1. EMBO J 2010; 29: 606-618.

90. Maejima Y, Kyoi S, Zhai P, Liu T, Li H, Ivessa A et al. Mst1 inhibits autophagy by promoting the interaction between Beclin1 and Bcl-2. Nat Med 2013; 19: 1478-1488.

91. Pattingre S, Bauvy C, Carpentier S, Levade T, Levine B, Codogno P. Role of JNK1-dependent Bcl-2 phosphorylation in ceramide-induced macroautophagy. J Biol Chem 2009; 284: 2719-2728.

92. He C, Bassik MC, Moresi V, Sun K, Wei Y, Zou Z et al. Exercise-induced BCL2-regulated autophagy is required for muscle glucose homeostasis. Nature 2012; 481: 511-515
93. Levine B, Sinha S, Kroemer G. Bcl-2 family members: dual regulators of apoptosis and autophagy. Autophagy 2008; 4: 600-606.

94. Luo S, Garcia-Arencibia M, Zhao R, Puri C, Toh PP, Sadiq O et al. Bim inhibits autophagy by recruiting Beclin 1 to microtubules. Mol Cell 2012; 47: 359-370.

95. Zhang H, Bosch-Marce M, Shimoda LA, Tan YS, Baek JH, Wesley JB et al. Mitochondrial autophagy is an HIF-1-dependent adaptive metabolic response to hypoxia. J Biol Chem 2008; 283: 10892-10903.

96. Hanna RA, Quinsay MN, Orogo AM, Giang K, Rikka S, Gustafsson AB. Microtubuleassociated protein 1 light chain 3 (LC3) interacts with Bnip3 protein to selectively remove endoplasmic reticulum and mitochondria via autophagy. J Biol Chem 2012; 287 : 19094-19104.

97. Zhang T, Xue L, Li L, Tang C, Wan Z, Wang R et al. BNIP3 suppresses PINK1 proteolytic cleavage to promote mitophagy. J Biol Chem 2016; 291: 21616-21629.

98. Novak I, Kirkin V, McEwan DG. Zhang J, Wild P, Rozenknop A et al. Nix is a selective autophagy receptor for mitochondrial clearance. EMBO Rep 2010; 11: 45-51.

99. Ding WX, Ni HM, Li M, Liao Y, Chen X, Stolz DB et al. Nix is critical to two distinct phases of mitophagy, reactive oxygen species-mediated autophagy induction and Parkin-ubiquitinp62-mediated mitochondrial priming. J Biol Chem 2010; 285: 27879-27890.

100. Sandoval H, Thiagarajan P, Dasgupta SK, Schumacher A, Prchal JT, Chen M et al. Essential role for Nix in autophagic maturation of erythroid cells. Nature 2008; 454: 232-235.

101. Hollville E, Carroll RG, Cullen SP, Martin SJ. Bcl-2 family proteins participate in mitochondrial quality control by regulating Parkin/PINK1-dependent mitophagy. Mol Cell 2014; 55: 451-466.

102. Ciccia A, Elledge SJ. The DNA damage response: making it safe to play with knives. Mol Cell 2010; 40: 179-204

103. Bartek J, Lukas J. DNA damage checkpoints: from initiation to recovery or adaptation. Curr Opin Cell Biol 2007; 19: 238-245.

104. Kastan MB, Bartek J. Cell-cycle checkpoints and cancer. Nature 2004; 432: 316-323.

105. Shiloh Y, Ziv Y. The ATM protein kinase: regulating the cellular response to genotoxic stress, and more. Nat Rev Mol Cell Biol 2013; 14: 197-210.

106. Kamer I, Sarig R, Zaltsman Y, Niv H, Oberkovitz G, Regev L et al. Proapoptotic BID is an ATM effector in the DNA-damage response. Cell 2005; 122: 593-603.

107. Zinkel SS, Hurov KE, Ong C, Abtahi FM, Gross A, Korsmeyer SJ. A role for proapoptotic BID in the DNA-damage response. Cell 2005; 122: 579-591.

108. Oberkovitz G, Regev L, Gross A. Nucleocytoplasmic shuttling of BID is involved in regulating its activities in the DNA-damage response. Cell Death Differ 2007; 14: 1628-1634.

109. Maryanovich M, Oberkovitz G, Niv H, Vorobiyov L, Zaltsman Y, Brenner $O$ et al. The ATMBID pathway regulates quiescence and survival of haematopoietic stem cells. Nat Cell Biol 2012; 14: 535-541.

110. Maryanovich M, Gross AA. ROS rheostat for cell fate regulation. Trends Cell Biol 2013; 23 : 129-134.

111. Tasdogan A, Kumar S, Allies G, Bausinger J, Beckel F, Hofemeister $\mathrm{H}$ et al. DNA damageinduced HSPC malfunction depends on ROS accumulation downstream of IFN-1 signaling and Bid mobilization. Cell Stem Cell 2016; 19: 752-767.

112. Liu Y, Bertram CC, Shi Q, Zinkel SS. Proapoptotic Bid mediates the Atr-directed DNA damage response to replicative stress. Cell Death Differ 2011; 18: 841-852.

113. Liu Y, Vaithiyalingam S, Shi Q, Chazin WJ, Zinkel SS. BID binds to replication protein A and stimulates ATR function following replicative stress. Mol Cell Biol 2011; 31: 4298-4309.

114. Liu Y, Aiello A, Zinkel SS. Bid protects the mouse hematopoietic system following hydroxyurea-induced replicative stress. Cell Death Differ 2012; 19: 1602-1612.

115. Biswas S, Shi Q, Wernick A, Aiello A, Zinkel SS. The loss of the BH3-only Bcl-2 family member Bid delays T-cell leukemogenesis in Atm-/- mice. Cell Death Differ 2013; 20: 869-877.

116. Gross A, Zaltsman $Y$, Maryanovich M. The ATM-BID pathway plays a critical role in the DNA damage response by regulating mitochondria metabolism. Cell Death Differ 2016; 23: 182.

117. Zinkel SS, Yin XM, Gross A. Rejuvenating Bi(d)ology. Oncogene 2013; 32: 3213-3219.

118. Wiese C, Pierce AJ, Gauny SS, Jasin M, Kronenberg A. Gene conversion is strongly induced in human cells by double-strand breaks and is modulated by the expression of BCL-x(L). Cancer Res 2002; 62: 1279-1283.

119. Yu H, Shen H, Yuan Y, XuFeng R, Hu X, Garrison SP et al. Deletion of Puma protects hematopoietic stem cells and confers long-term survival in response to high-dose gamma-irradiation. Blood 2010; 115: 3472-3480 